\title{
Giant subcutaneous abscess after percutaneous endoscopic gastrostomy
}

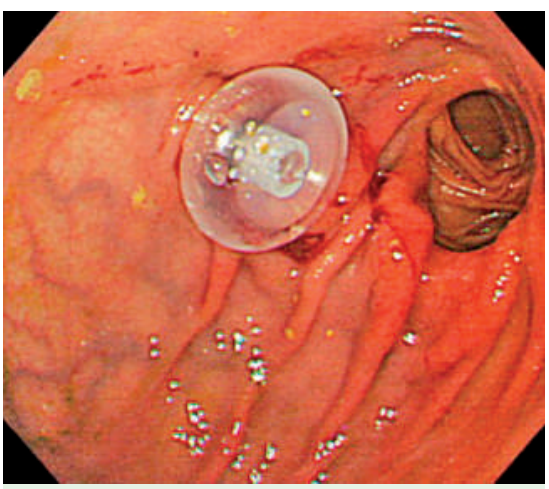

Fig. 1 The gastrostomy tube was placed in the stomach.

A 69-year-old man was admitted to our hospital with dysphagia, which had resulted from multiple cerebral infarctions. A 20-Fr gastrostomy tube was inserted under endoscopic guidance. The procedure was uneventful, and antibiotics were not administered ( Fig. 1). Although the skin around the fistula showed no clinical signs of abnormality, the patient's abdominal pain increased. Computed tomography showed a lowdensity area in the left subcutaneous space ( Fig.2), and Enterococcus faecium was identified in cultures of pus from the stoma. The subcutaneous abscess was treated by surgical drainage and he was given sulbactam/cefoperazone. The abscess responded well to treatment and disappeared 2 months after insertion of the percutaneous endoscopic gastrostomy.

Peristomal wound infection after insertion of a percutaneous endoscopic gastrostomy is usually caused by oral bacteria. In the present case, however, a giant subcutaneous abscess was caused by Enterococcus faecium. The patient had undergone a Billroth II distal gastrectomy for the treatment of a peptic ulcer. The first explanation for the formation of this giant abscess in this patient could be that the resection of the pylorus and the lack of gastric acid might have enabled enterobacteria to flow back into the stomach. Secondly, because the gastrectomy scar was known to be hypovascular, the patient's subcutaneous tissue could have been more susceptible to infection.

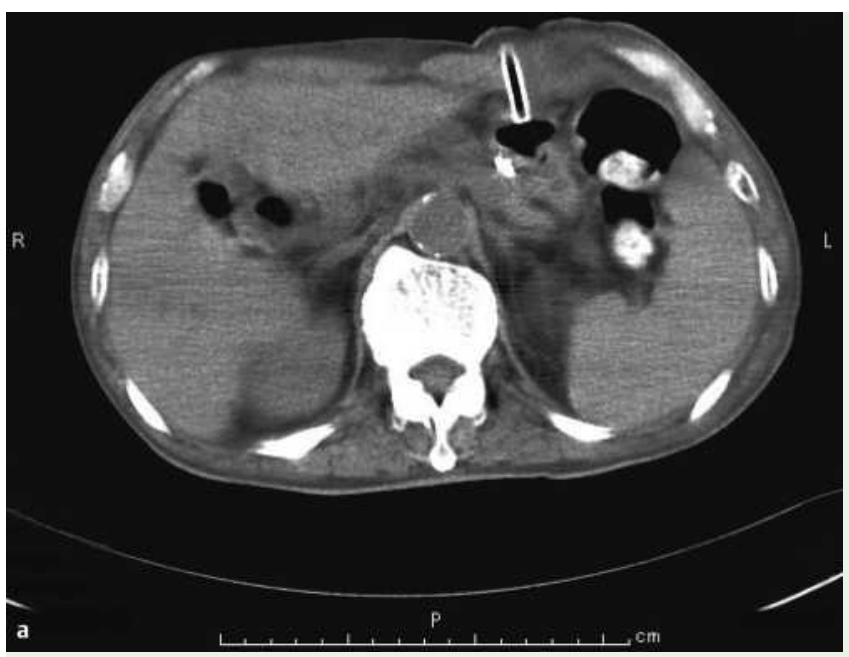

Fig. 2 Computed tomographic views showing a large lowdensity area in the left subcutaneous space.

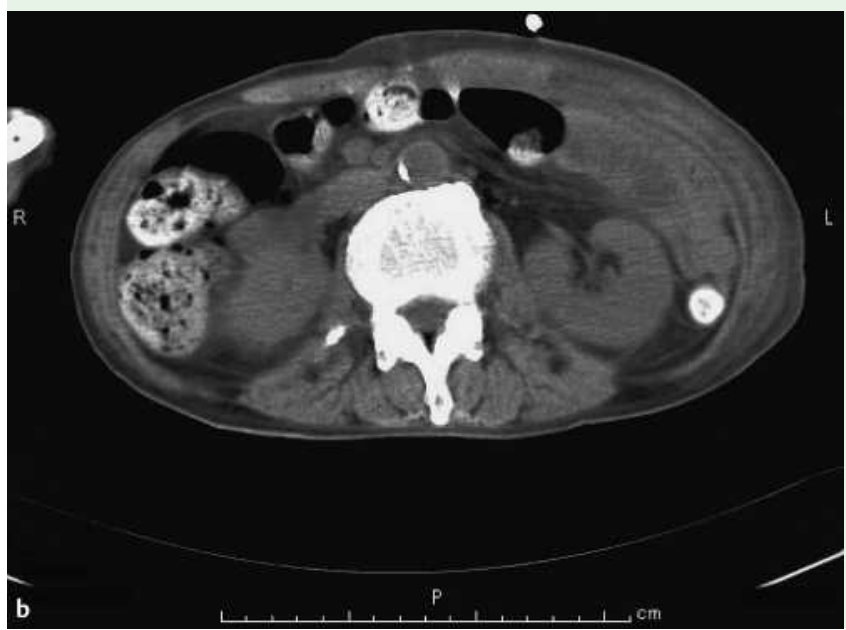

Endoscopy_UCTN_Code_CPL_1AH_2AI

Bibliography

DOI 10.1055/s-2007-966598

Endoscopy 2007; 39: E264

H. Sakai ${ }^{1}$, M. Inamori ${ }^{1}$, T. Sato ${ }^{1}$, K. Akimoto ${ }^{1}$, T. Akiyama ${ }^{1}$, K. Fujita ${ }^{1}$, M. Yoneda ${ }^{1}$, H. Takahashi ${ }^{1}$, A. Goto ${ }^{1}$, A. Kusakabe ${ }^{1}$, Y. Abe ${ }^{1}$, H. Kirikoshi ${ }^{1}$, K. Kubota ${ }^{1}$, N. Ueno ${ }^{1}$, Y. Rino ${ }^{2}$,

A. Nakajima

Gastroenterology Division, Yokohama City University School of Medicine, Yokohama, Japan

2 Department of Surgery, Yokohama City University School of Medicine, Yokohama, Japan (c) Georg Thieme Verlag KG Stuttgart · New York . ISSN 0013-726X

Corresponding author

\section{Inamori, MD}

Gastroenterology Division

Yokohama City University School of Medicine

3-9 Fukuura

Kanazawa-ku

Yokohama 236-0004

Japan

Fax: +81-45-784-3546

inamorim@med.yokohama-cu.ac.jp 